\title{
The effect of increasing lifespan and recycling rate on carbon storage in wood products from theoretical model to application for the European wood sector
}

\author{
Pau Brunet-Navarro ${ }^{1,2}$ (D) Hubert Jochheim ${ }^{1}$. \\ Bart Muys $^{2}$
}

Received: 1 March 2016 / Accepted: 8 August 2016 / Published online: 9 September 2016

(C) Springer Science+Business Media Dordrecht 2016

\begin{abstract}
The use of wood products is often promoted as a climate change mitigation option to reduce atmospheric carbon dioxide concentrations. In previous literature, we identified longevity and recycling rate as two determining factors that influence the carbon stock in wood products, but no studies have predicted the effect of improved wood use on carbon storage over time. In this study, we aimed at evaluating changes in the lifespan and the recycling rate as two options for enhancing carbon stock in wood products for different time horizons. We first explored the behaviour over time of both factors in a theoretical simulation, and then calculated their effect for the European wood sector of the future. The theoretical simulation shows that the carbon stock in wood products increases linearly when increasing the average lifespan of wood products and exponentially when improving the recycling rate. The emissions savings under the current use of wood products in Europe in 2030 were estimated at $57.65 \mathrm{Mt}$ carbon dioxide $\left(\mathrm{CO}_{2}\right)$ per year. This amount could be increased $5 \mathrm{Mt} \mathrm{CO}_{2}$ if average lifespan increased $19.54 \%$ or if recycling rate increased $20.92 \%$ in 2017 . However, the combination of both strategies could increase the emissions saving almost $5 \mathrm{MtCO}_{2}$ more by 2030 . Incrementing
\end{abstract}

Electronic supplementary material The online version of this article (doi:10.1007/s11027-016-9722-z) contains supplementary material, which is available to authorized users.

Pau Brunet-Navarro

Pau.Brunet@zalf.de

Hubert Jochheim

Hubert.Jochheim@zalf.de

Bart Muys

Bart.Muys@ees.kuleuven.be

1 Leibniz Centre for Agricultural Landscape Research (ZALF), Institute of Landscape Systems Analysis, Eberswalder Straße 84, 15374 Müncheberg, Germany

2 Division Forest, Nature and Landscape, University of Leuven, Celestijnenlaan 200E-2411, BE-3001 Leuven, Belgium 
recycling rate of paper and paperboard is the best short-term strategy (2030) to reduce emissions, but elongating average lifespan of wood-based panels is a better strategy for longer term periods (2046).

Keywords Cascade use $\cdot$ Climate change mitigation · Modelling $\cdot$ Carbon sequestration $\cdot$ Time scale

\section{Introduction}

The reduction of greenhouse gas (GHG) emissions has become a global goal since the signing of the United Nations Framework Convention on Climate Change (UN FCCC) in 1992. The Intergovernmental Panel on Climate Change (IPCC 2013) identified anthropogenic GHG emissions as one of the main drivers of climate change. Forests are large carbon pools that sequester atmospheric carbon dioxide by photosynthesis. Harvested wood from forests, of which about $50 \%$ of the dry weight is carbon, is used to manufacture wood products that can further store the sequestered carbon. During the first commitment period of the Kyoto Protocol (2008-2012), carbon stored in forests was accounted for, but carbon in wood products was not. However, after the 17th Conference of the Parties in Durban (COP17) in 2011, wood products were recognized as accounted carbon pools for the second commitment period of the UN FCCC Kyoto Protocol for Annex I parties. The Paris Agreement signed at 21st UN FCCC Conference of the Parties in 2015 aims at keeping global warming within $2{ }^{\circ} \mathrm{C}$ thanks to the Intended Nationally Determined Contributions. In that context, a smart use of wood products can contribute to achieve the reduced emission goals.

Carbon stocks and fluxes in wood products are estimated using wood product models (Brunet-Navarro et al. 2016). In 2000, carbon stock in European Union (EU) forest was estimated to be 13.749 Gt. carbon (C) (Eggers 2002), distributed between trees (6.89 Gt C), forest soils $(6.086 \mathrm{Gt} \mathrm{C})$ and wood products $(0.769 \mathrm{Gt} \mathrm{C})$. Among the whole forestry sector, the carbon share in wood products varies between countries and regions (e.g. $5 \%$ in the United States of America (USA) (Smith et al. 2004), 6 \% in Europe (Eggers, 2002; Karjalainen et al. 2003) and $13 \%$ in Canada (Kurz et al. 1992)). As to the carbon flux, the carbon dioxide sequestrated by wood products in Europe (EU-28) was estimated 44 Mt. per year (equivalent to $12 \mathrm{Mt}$. C per year) (about $10 \%$ of the carbon dioxide sequestrated by forests) (Pilli et al. 2015). The lifespan (Kohlmaier et al. 2007; Waterworth \& Richards 2008; Garcia et al. 2010; Wiesmeier et al. 2012) and recycling rate (Dewar \& Cannell 1992; Kurz et al. 1992) of wood products have been identified as two main factors influencing the amount of carbon in wood products. In line with these results, strategies to reduce GHG emissions in the forestry sector should aim at increasing products' lifespan and recycling rate.

Country targets for reducing GHG emissions are designed for the short to medium term. For instance, the Intended Nationally Determined Contributions of the EU set a goal of reducing GHG emissions by $40 \%$ by 2030 compared to 1990 levels. It is therefore likely that any selected strategy will have to demonstrate its effectiveness and efficiency in the short and medium term, including for increasing carbon stock in wood products. The timing of wood product carbon emissions under business-as-usual scenarios has been analysed for some countries (Mason Earles et al. 2012). Other studies analysed the effect of alternative forest management (Fortin et al. 2012; Klein et al. 2013; Knauf et al. 2015) or the effect of climate change (Karjalainen et al. 2003) on wood product carbon stock. Höglmeier et al. (2014) compared the impacts to produce particleboards using virgin wood or waste wood. However, 
studies predicting effects of improved use of wood products on carbon storage in a timeexplicit way are lacking.

In this study, we aimed at evaluating changes in lifespan and recycling rate as two options for enhancing carbon storage in wood products for different time horizons. We performed two different exercises. We first made a theoretical simulation exercise to explore the effect over time of stepwise increasing the average lifespan and recycling rate of wood products on the carbon stock. Secondly, we executed a more practical exercise with EU data to analyse how average lifespan or recycling rate should increase to achieve a concrete target of GHG emissions reduction at a certain moment.

\section{Methods}

We developed a model to estimate carbon stored in different categories of wood products at time t. The model is simple, consisting of two parameters (average lifespan $\left(l_{i}\right)$ and recycling rate $\left(r_{i}\right)$ ) and a single state variable $\left(C_{\mathrm{p}}\right)$ which represents the carbon content in an unique product commodity (p) (e.g. sawn wood, wood-based panels or paper and paperboard). The variable $C_{\mathrm{p}}$ is defined by the sum of sub-variables $\left(c_{i}\right)$, which represent the carbon stored in products produced at different years $(i)$ from harvested $\left(H_{i}\right)$ and recycled wood $\left(R_{i}\right)$ (Eqs. 1, 2 and 3). We used the distributed approach as described by Marland et al. (2010). The parameters of average lifespan and recycling rate are time-dependent and define the removal rate of the product produced at time $t$. We used time steps of 1 year.

$$
\begin{gathered}
C_{\mathrm{p}}(t)=\sum c_{i}\left(t_{i}\right) \\
c_{i}\left(t_{i}\right)=\left(H_{i}+R_{i}\right) \times\left(1-\mathrm{CDF}_{i}\left(t_{i}\right)\right) \\
R_{i}=r_{i} \times \sum\left(c_{1 \rightarrow i}\left(t_{i}-1\right)-c_{1 \rightarrow i}\left(t_{i}\right)\right)
\end{gathered}
$$

The product removal rate was defined using the cumulative distribution function (CDF) of a normal distribution, also used in other studies (e.g. Muller et al. (2004)). The normal distribution is defined with a mean and a standard deviation. The mean corresponds to the average lifespan of the product under analysis produced at year $i$. The standard deviation was arbitrarily defined as one third of the average lifespan (Eq. 4) (Supplementary Information 1). The normal distribution was calculated using the function dnorm (in the package stats version 3.2.0) in R software version 3.0.1.

$$
\mathrm{sd}_{i}=l_{i} / 3
$$

In the literature, besides using the normal distribution to define the cumulative distribution function, other distributions have been used such as linear (Winjum et al. 1998), exponential (Karjalainen et al. 1994) or gamma distributions (Klein et al. 2013). All of them have been proposed using expert knowledge, but none of them have ever been validated due to lack of data. We omitted linearly and exponentially distributed functions, because we assume a maximum rate of decay over a product's average lifespan, but not immediately after production. In other words, most of the products designed to be in use, for example 25 years, will be 
removed around 25 years after production, but not the next year after their production. We believe that gamma distribution is the closest to reality because it allows representation of asymmetric behaviour. However, it was excluded because it is difficult to estimate the required parameters for each average lifespan included in this study due to lack of data. Moreover, wood products' removal rates defined using normal distributions are similar to gamma distributions because they are not very asymmetric as can be seen in studies that applied it (e.g. Marland and Marland (2003) or Klein et al. (2013)).

Avoided emissions of carbon dioxide equivalents are assumed to be equal to carbon stocks increments once they are transformed using a correction factor ( $1 \mathrm{t} \mathrm{C}$ equals $44 / 12 \mathrm{t} \mathrm{CO}_{2}$ ).

\subsection{Theoretical simulation exercise}

When selecting scenarios, the focus was placed on covering all possible combinations of average lifespan and recycling rate. Recycling scenarios ranged from 0 to $95 \%$. Higher recycling rates were avoided because they would be impossible to achieve in reality. Average lifespan scenarios ranged from 5 to 100 years. The maximum average lifespan value of 100 years was selected from the list of half-life values (equivalent to the average lifespan when using normal distribution) compiled in the review study of Pingoud et al. (2003).

Since the interval between minimum and maximum average lifespan and recycling rates included 95 units each, we decided to split them with the same number of intervals (19), thus using increments of 5 years and $5 \%$, respectively, which are obviously different units that cannot be directly compared. The model was run for 400 combinations of scenarios (20 different recycling rates combined with 20 different average lifespan).

Special attention was placed on the three selected product commodities of sawn wood, wood-based panels and paper and paperboard. According to the IPCC recommendations (IPCC, 2014), the average lifespan of the selected products are 35, 25 and 2 years, respectively. Since an average lifespan of 2 years was not included in this simulation exercise, we represented the average lifespan of paper and paperboards with 5 years. The recycling percentages estimated were 30,10 and $70 \%$ for sawn wood, wood-based panels and paper and paperboards, respectively. These percentages were approximated from other studies: sawn wood from Eggers (2002) and Schelhaas et al. (2004), wood-based panels from Eggers (2002); Schelhaas et al. (2004) and Skog (2008) and paper and paperboards from Eggers (2002) and Mantau (2012). However, these studies used different groups to classify products, which make comparisons difficult.

In a first phase, we estimated carbon stock in wood products at steady state under the assumption of constant production (Fig. 1). The total amount of carbon was the sum of carbon stock in products produced in successive years. The steady state was achieved when the total carbon stock increased less than $1 \%$ of the input. This threshold was defined to avoid excessive time with very low carbon stock increments.

In a second phase, we estimated the carbon stock oscillation during the switch from old product characteristics to new ones (higher average lifespan or higher recycling rate) (Fig. 1). We first estimated the carbon stock curve derived by the production stop of products with old characteristics. Then, we estimated the curve representing the carbon stock of products with new characteristics. The sum of both curves represented the total carbon stock of this product commodity.

Finally, we calculated the difference between carbon stock at time zero of the second phase and subsequent years to estimate the temporal development of carbon stock changes. 


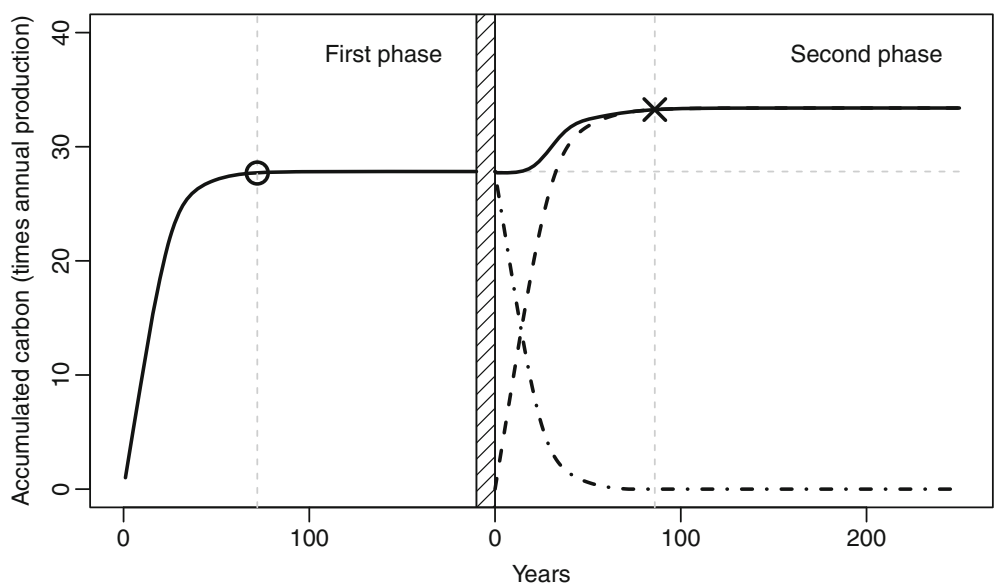

Fig. 1 Illustration of the method used to simulate carbon stock over time. In the first phase, the carbon stock in a product category (here, wood-based panels as an example) is simulated for conditions of constant production with an average lifespan of 25 years and a recycling rate of $10 \%$. The solid line represents the carbon stock accumulation over time for this scenario, and the circle represents the time and carbon amount at steady state. The second phase starts when conditions change to an increased average lifespan of wood-based panels from 25 to 30 years. The development of carbon stock in this second phase is represented by a solid line, which is the resultant of the dashed-dotted line representing product removal of wood-based panels with 25-year average lifespan (and a $10 \%$ recycling rate) after production of phase 1 stops at time zero of the second phase, and the upward sloping dashed line representing carbon stock development due to the constant production of new woodbased panels with an increased average lifespan of 30 years (and a $10 \%$ recycling rate) from time zero of the second phase onwards. The cross represents the year and the amount of carbon at steady state

\subsection{Application to the European wood sector}

We applied the same model approach with real data from Europe (EU-28). We used annual production of the three selected products, their average lifespan and their recycling rate to estimate the current carbon stock in wood products.

The annual production of a given product was estimated using the United Nations Food and Agriculture Organization Statistics (FAOSTAT) online database (Food Agriculture Organization of the United Nations 2014). Each product category used in this study is an aggregate of different items as shown in Table 1. Information on annual production was available from 1961 to 2014. The last value reported for fibreboard category was on 1994 . From 1995 onwards, this category was split into medium density fibreboards and hardboards. We started running the model from year 1800 for the spin-up. At this year, the estimated annual production was zero $\mathrm{t} C$ for all products. The production of successive years was estimated with a linear increase until the first value reported by FAOSTAT was achieved at year 1961. Future production was estimated using the forecast increases in percentages from Mantau and Saal (2010). This report estimated that till 2020 wood consumption would increase by $15.4 \%$ compared to 2010 values. The last year of production estimations available from FAOSTAT was 4 years later (2014). Therefore, we estimated a proportional increase for the last 6 years (2014-2020) of $9.24 \%$. The same production increase from 2020 to 2030 of $17.2 \%$ estimated by Mantau and Saal (2010) was used for the last simulated years of this study (2020-2046). Conversion factors to estimate carbon content from volumes reported in FAOSTAT were extracted from IPCC (2014) (Table 1). 
Table 1 Description of the FAOSTAT data used to estimate wood production

\begin{tabular}{llllll}
\hline Product category & Item name & $\begin{array}{l}\text { Item } \\
\text { code }\end{array}$ & $\begin{array}{l}\text { Time series } \\
\text { available }\end{array}$ & $\begin{array}{l}\text { Original } \\
\text { unit }\end{array}$ & $\begin{array}{l}\text { Conversion } \\
\text { factor to t C }\end{array}$ \\
\hline Sawn wood & Sawn wood (coniferous) & 1632 & $1961-2014$ & $\mathrm{~m}^{3}$ & 0.225 \\
& $\begin{array}{l}\text { Sawn wood } \\
\text { (non-coniferous) }\end{array}$ & 1633 & $1961-2014$ & $\mathrm{~m}^{3}$ & 0.280 \\
Wood-based panels & Veneer sheets & 1634 & $1961-2014$ & $\mathrm{~m}^{3}$ & 0.253 \\
& Plywood & 1640 & $1961-2014$ & $\mathrm{~m}^{3}$ & 0.267 \\
& Particle board & 1646 & $1961-2014$ & $\mathrm{~m}^{3}$ & 0.269 \\
& Hardboard & 1647 & $1995-2014$ & $\mathrm{~m}^{3}$ & 0.335 \\
& MDF & 1648 & $1995-2014$ & $\mathrm{~m}^{3}$ & 0.295 \\
& Fibreboard, compressed & 1649 & $1961-1994$ & $\mathrm{~m}^{3}$ & 0.315 \\
& Insulating board & 1650 & $1961-2014$ & $\mathrm{~m}^{3}$ & 0.075 \\
& Paper and paperboard & 1876 & $1961-2014$ & $\mathrm{~T}^{3}$ & 0.386 \\
\hline
\end{tabular}

FAOSTAT data includes recycled products. Therefore, we had to estimate the production with virgin wood. This transformation was performed for each product type using its recycling rate. The factor of virgin wood production over the total production was estimated by extracting the recycling value to $100 \%$. For example, for wood-based panels with $10 \%$ of recycling rate, we estimated that only $90 \%$ (100 minus 10) of the volume reported from FAOSTAT was produced with virgin wood.

In this practical exercise, instead of simulating stepwise increments of average lifespan and recycling rate as in the theoretical exercise, we defined a target of GHG emission reduction and calculated how much the average lifespan or the recycling rate should increase to achieve it. Product characteristics of average lifespan and recycling rate were assumed to improve abruptly in 2017. Since a European target of GHG emission reduction for the land use, land use change and forestry sector does not exist, we defined an arbitrarily one of additional reduction of $5 \mathrm{Mt}$. of $\mathrm{CO}_{2}$ in 2030. The year 2030 was chosen because the targets in the Intended Nationally Determined Contributions of EU are defined for this year. Average lifespan increments (inc $\left.c_{l}\right)$ were defined applying the same proportion to current values of all products (e.g. an increment of 1.1 times on current average lifespan $\left(l_{c}\right)$ of wood-based panels will suppose a rise from 25 to 27.5 years) (Eq. 5). The increments on recycling rate $\left(i n c_{r}\right)$ were calculated differently because of two reasons. Firstly, they are limited at $100 \%$. Secondly, we assume that the effort to increase it on a product with a high recycling rate is bigger than the effort to increase it on another product with a low recycling rate. Thus, we added to the current value of recycling rate $\left(r_{c}\right)$ a portion of the percentage needed to achieve $100 \%$ (e.g. an increment of 0.1 on current recycling rate of wood-based panels will suppose a rise from 10 to $19 \%$ ) (Eq. 6).

$$
\begin{gathered}
l_{\mathrm{n}}=l_{\mathrm{c}} \times i n c_{l} \\
r_{\mathrm{n}}=r_{\mathrm{c}}+\left(100-\mathrm{r}_{\mathrm{c}}\right) \times i n c_{r}
\end{gathered}
$$

where $l_{\mathrm{n}}$ and $r_{\mathrm{n}}$ are new average lifespan and new recycling rate values, respectively. We also estimated the climate change mitigation effect if both increases were combined. All calculations were performed using $\mathrm{R}$ software (version 3.0.1). 


\section{Results}

\subsection{Theoretical simulation exercise}

The purpose of this simulation exercise was to explore the climate change mitigation potential of improved wood product use by analysing carbon stock changes in wood products over time due to increases of average lifespan and recycling rate. The carbon stock in a specific wood product needs between 10 years (for products with an average lifespan of 5 years and a $0 \%$ recycling rate) and 9062 years (for products with an average lifespan of 100 years and a $95 \%$ recycling rate) to achieve steady state conditions from the start of its production (end of phase 1 and end of phase 2 with new conditions according to Fig. 1) (Fig. 2a). The time required to reach steady state is linearly dependent on the average lifespan and exponentially dependent on the recycling rate. Carbon stock in short-lived products with a low recycling rate achieves the steady state the earliest. The steady state was achieved after 69, 72 and 162 years for paper and paperboard (with an assumed 5-year average lifespan and a $70 \%$ recycling rate), woodbased panels (with an assumed 25-year average lifespan and a $10 \%$ recycling rate) and sawn wood (with an assumed 35-year average lifespan and a $30 \%$ recycling rate), respectively (Fig. 2b). Once all products reached the steady state, the carbon stock was compared among product categories. Carbon stored in different products showed a linear increase when extending a product's average lifespan and an exponential increase when a rising product recycling rate was used (Fig. 2a), which logically reflects the same behaviour as we observed for the time needed for the spin-up to the steady state.

The carbon stock needed time to reach a new steady state when the characteristics of the use of wood products were improved, either by extending the average lifespan or increasing the recycling rate (Fig. 3). During the first 22 years, the carbon stock increased faster when extending average lifespan by 5 years than when increasing the recycling rate by $5 \%$ for all scenarios (Supplementary Video 1). An increased recycling rate started to be a better strategy at year 9, but only for products with the highest recycling rate $(90 \%)$. In following years, an increased recycling rate appeared to be a better option also for products with high recycling rates. When simulating all scenarios until reaching a new steady state, carbon stocks in long-lived products with high recycling rates increased more due to raising the recycling rate than extending the average lifespan (Fig. 3). In contrast, carbon stock in short-lived products with low recycling rates increased more by extending the average lifespan.

\subsection{Application to the European wood sector}

Our results showed that the total carbon stock in European (EU-28) wood products overall was estimated to be $0.819 \mathrm{Gt} \mathrm{C}$ in $2000,1.055 \mathrm{Gt} \mathrm{C}$ in 2016 and $1.257 \mathrm{Gt} \mathrm{C}$ in 2030. The amount in 2016 was distributed between sawn wood products $(0.653 \mathrm{Gt} \mathrm{C})$ with an assumed average lifespan of 35 years and a recycling rate of $30 \%$, wood-based panels $(0.330 \mathrm{Gt} \mathrm{C})$ with an assumed average lifespan of 25 years and a recycling rate of $10 \%$ and paper and paperboard $(0.072 \mathrm{Gt} \mathrm{C})$ with an assumed average lifespan of 2 years and a recycling rate of $70 \%$.

The annual reduction of emissions due to wood product use in 2016 was $46.93 \mathrm{Mt}$ $\mathrm{CO}_{2}$ (Fig. 4). The reduction of emissions in 2030 increased up to $57.65 \mathrm{Mt} \mathrm{CO}_{2}$ per year 
Fig. 2 State variables of carbon storage in wood products at the steady state. Results of the theoretical simulation exercise at the end of the first phase. a Carbon stock at the steady state. b Time needed to achieve the steady state. The circle represents paper and paperboard (5-year average lifespan and $70 \%$ recycling rate). The square represents wood-based panels (25-year average lifespan and $10 \%$ recycling rate). The triangle represents sawn wood (35year average lifespan and $30 \%$ recycling rate)
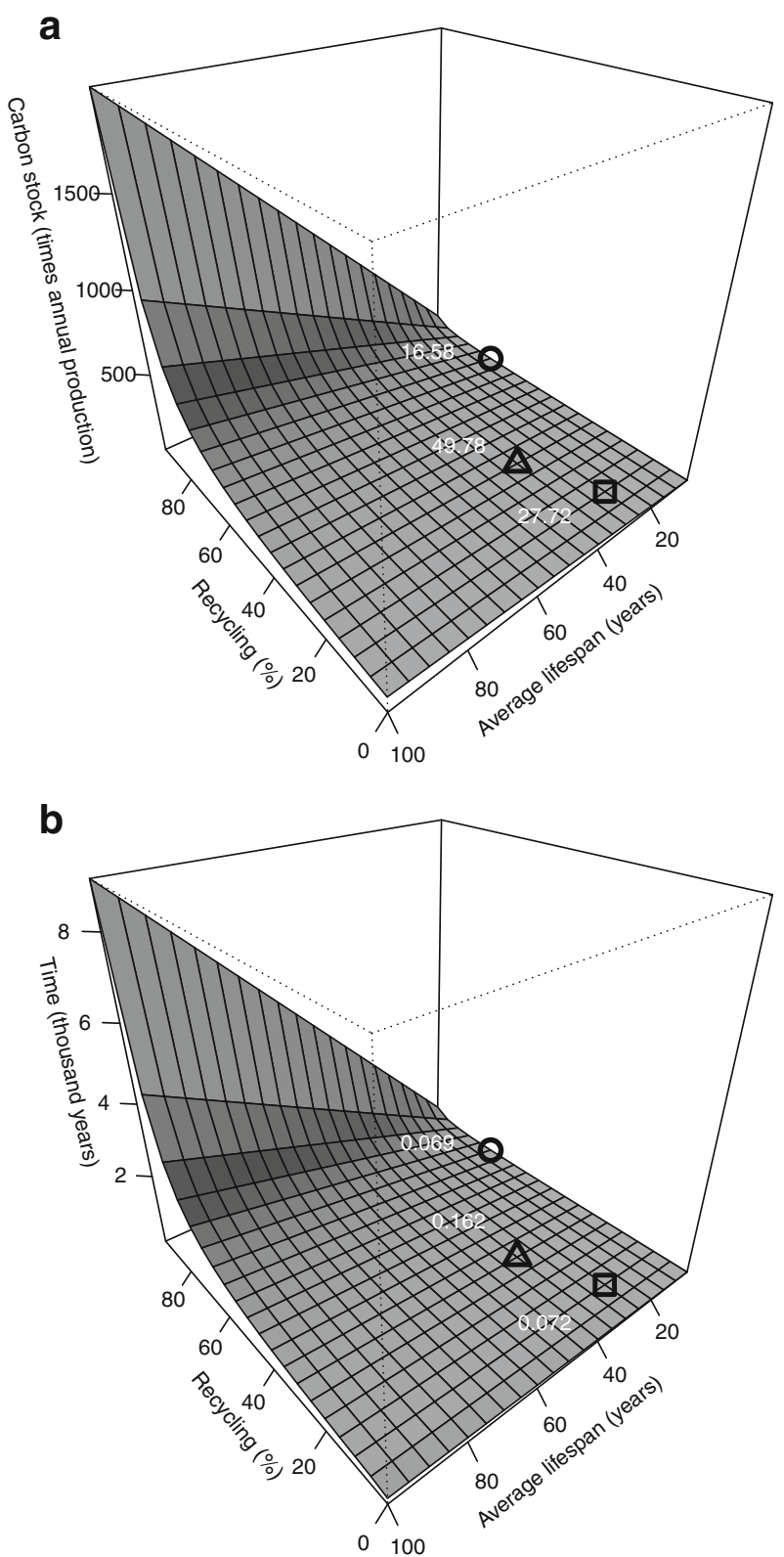

under the business as usual scenario. Average lifespan of wood products should increase $19.54 \%\left(\right.$ inc $\left._{l}=1.1954\right)$ to increase the reduction of emissions by an extra $5 \mathrm{Mt} \mathrm{CO}_{2}$ in 2030. Recycling rate should increase $20.92 \%\left(i n c_{r}=0.2092\right)$ to achieve the same level of emissions reduction. When both increments were combined, the reduction of emissions in 2030 achieved $67.62 \mathrm{Mt} \mathrm{CO}_{2}$. The reduction of emissions after 2030 due to elongation of lifespan was bigger than increments on recycling rate (Fig. 4). Each product contributed differently to reduce European emissions (Fig. 5). 

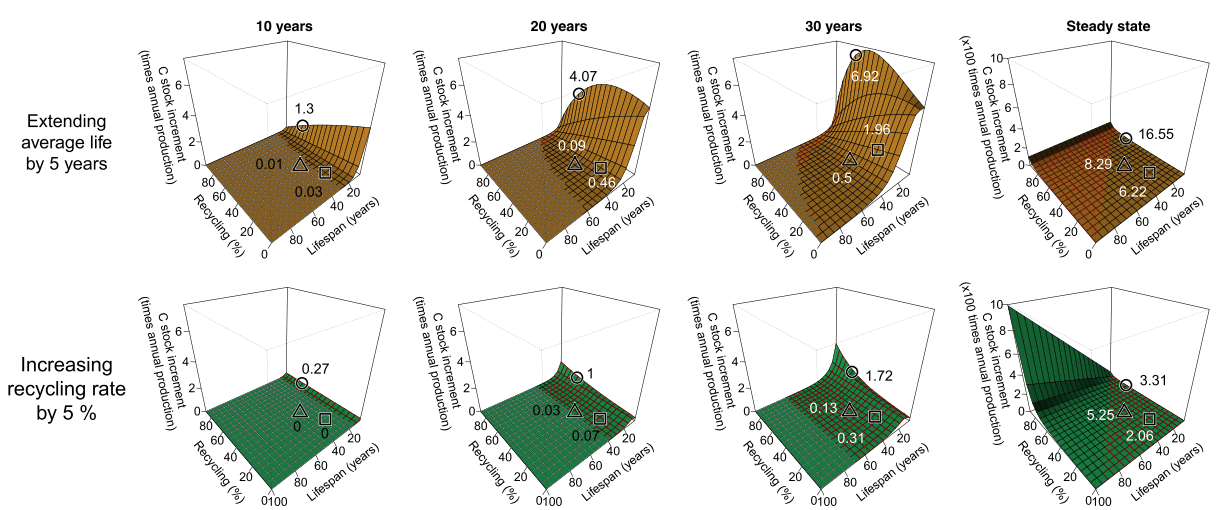

Fig. 3 Carbon stock increment after improving wood product use characteristics. Carbon stock increase is represented 10, 20 and 30 years after extending the average lifespan by 5 years (upper figures in yellow) and increasing the recycling rate by $5 \%$ (lower figures in green). The carbon stock increment is also represented at reaching a new steady state. The circle, square and triangle represent carbon stock increases of paper and paperboard (5-year average lifespan and a $70 \%$ recycling rate), wood-based panels (25-year average lifespan and a $10 \%$ recycling rate) and sawn wood products (35-year average lifespan and a $30 \%$ recycling rate). Red grids and black grids indicate respectively scenarios where the carbon stock increase is lower or higher than the alternative scenario of extending the average lifespan or increasing the recycling rate. White grid indicates increments lower than 0.01 times annual production

\section{Discussion}

With the approach used in this study, which excludes industrial emissions and trade, the carbon stock increment for a certain period of time is equivalent to the reduction of carbon emissions from wood decomposition during the same period. Under a scenario of constant production, wood products are neither a sink nor a source of carbon once they have achieved steady state. When improving the product use characteristics in terms of lifespan or recycling rate, carbon stock increments will lead to a new steady state where carbon stock increments are again equal to the reductions of emissions from the wood product pool.

For a full view on the carbon balance of the forest sector, besides carbon stock change and industrial emissions, the substitution effect should be included. The substitution effect refers to the reduction of emissions from industries producing alternative products due to their reduction of activity because demand is covered for an increased production of wood products. Emissions of

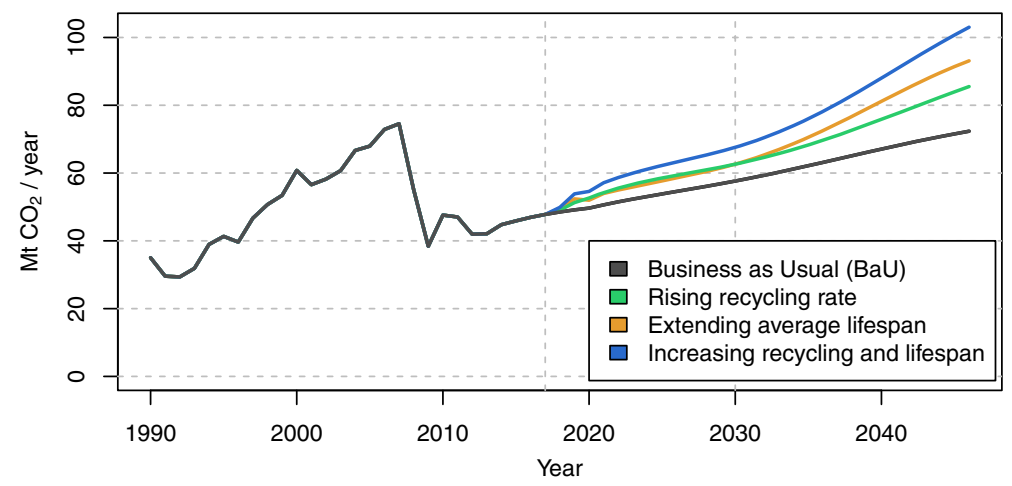

Fig. 4 Atmospheric $\mathrm{CO}_{2}$ removals in Europe (EU-28) due to wood product use under different scenarios 
Fig. 5 Increment of atmospheric $\mathrm{CO}_{2}$ absorbed in Europe (EU-28) due to improvement of average lifespan $\left(\right.$ inc $\left._{l}=1.1954\right)$, recycling rate $\left(\right.$ inc $\left._{r}=0.2092\right)$ or both together compared to the business-as usual-scenario

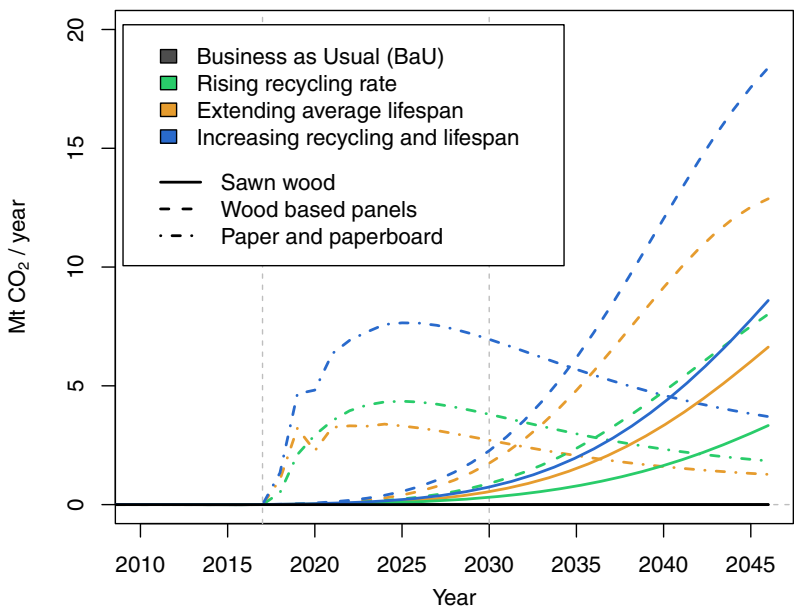

wood processing industries can be compared with emissions for the production of equivalent alternative materials by applying a life cycle analysis (Werner et al. 2010). Climate change mitigation options regarding the use of wood products may be different when including industrial emissions and substitution effects besides carbon stock change.

Due to the approach used in this work, changes in product characteristics have only been applied to new products. In reality, this situation is true for some but probably not all cases. Changes in product characteristics could also affect products already in use. For instance, from the moment when recycling rate improves, any removed products could be already recycled at the new rate. In this case, carbon stock changes would occur more quickly than estimated here. On the other hand, changes in product characteristics could require a transition period before they are fully implemented, with a consequently slower effect on carbon stock. The abrupt changes assumed in this study simulate a scenario in between these two cases of faster and slower effects on carbon stock. In addition, changes in product characteristics could derive on a reduction of demand of virgin wood and keep the same carbon stock levels as in the business as usual scenario.

Our simulation allocated recycled products to the same product category. This is a simplification of reality. In the real world, recycling leads to degradation, so recycled products are often of lower quality, including in terms of life expectancy. Thus, recycling effects may be overestimated with our model approach.

This study has compared the carbon storage capacity of products with different characteristics, first in the theoretical exercise with an equal and constant amount of production among products, and after that with a differentiated input between products and changes over time in a real case for Europe. In both cases, long-lived products were identified as having the greatest capacity to store carbon. Other studies using the second approach only have also identified long-lived products as the best option for storing carbon (Harmon et al. 1996; Werner et al. 2006; Eriksson et al. 2007; Fortin et al. 2012). Moreover, Klein et al. (2013) and Werner et al. (2010) highlighted the rate of recycling as one important characteristic for increasing carbon stock in wood products. Our results confirmed the relevance of the recycling rate effect on the carbon stock, especially when products achieved high rates like paper and paperboard did. However, since both strategies are compatible and there is no trade-off between them (as Fig. 2 shows), it is logical to combine both. In addition, according to studies such as Höglmeier et al. (2015), recycling wood has additional benefits for climate because harvested wood is used 
more efficiently. Thanks to this higher efficiency, more products can be produced from a limited forest area and increase the total carbon stock.

\subsection{Theoretical simulation exercise}

In the theoretical exercise, we observed that carbon stock in wood products has a linear dependence on its average lifespan and an exponential relationship to its recycling rate. The linear dependence after increasing the lifespan is explained by the fact that it affects the total amount of carbon only once. On the other hand, when the recycling rate increases, the effect is repeated every time the product is recycled, triggering an increment of the increase; this is translated into exponential behaviour. Thus, products storing the maximum carbon stock are those with the highest recycling percentages, mainly when these are higher than 70-80\%, in combination with long average lifespan. Unfortunately, in reality, it is difficult to achieve these high recycling rates due to logistics. In addition, the time required to increase carbon stocks in wood products by increasing the recycling rate up to these high levels is much longer than by increasing the average lifespan. The fastest increments in the increase of carbon stock resulted from extending the average lifespan of short-lived products such as paper and paperboard. However, increasing the lifespan of paper and paperboard products is maybe the least likely outcome due to current common uses and production processes of paper products.

\subsection{Application to the European wood sector}

The spin-up time period used to estimate the current carbon stock in European wood products was 217 years (1800-2016), which was long enough to reach the steady state for the three selected product types (see Fig. 2b). When using products with different characteristics, or models with different distribution functions, the minimum time series should be adjusted accordingly.

The amount of carbon stored in European (EU-28) wood products that we simulated (0.819 Gt $\mathrm{C}$ in 2000 and $1.055 \mathrm{Gt} \mathrm{C}$ in 2016) is comparable to the $0.769 \mathrm{Gt} \mathrm{C}$ estimated by Eggers (2002) for the EU-27 in 2000. This is a smaller amount of carbon, but still relevant, compared to the $11.153 \mathrm{Gt} \mathrm{C}$ stored in European forest biomass (EU-27) (Barredo et al. 2012). Although the production of paper and paperboard was the highest in terms of tonnes of carbon, this commodity does not store more carbon than others due to its short average lifespan. The highest emission reduction by 2030 happened when recycling rate of paper and paperboard products was increased (Fig. 5). However, improving average lifespan of wood-based panels is the best option for the longer term (by 2046). We observed that carbon stock in products with low average lifespan reacted fast to parameter changes, but have a lower effect at the long term. We also identified that increments in recycling rate are a better option than increments in lifespan when high recycling rate can be achieved, as it is for paper and paperboard. Thus, efforts to improve the use of paper and paperboard should be prioritized to achieve short-term targets (by 2030). However, to achieve more significant mitigation effects in the longer run (e.g. by 2046), efforts should be focused on products with longer average lifespan, especially on improving average lifespan of wood-based panels. This is the same behaviour as observed in the theoretical simulation exercise. Notice that strategies to increase average lifespan and recycling rate are not exclusive, and they can be combined to achieve higher mitigation benefits (Fig. 4). Notice also that the general conclusions can be applied in other continents with similar proportions of products production. 
We observed a strange behaviour of emissions saving when average lifespan of paper and paperboard was extended (Figs. 4 and 5). This strange behaviour disappeared when the standard deviation increased (e.g. $\left.\mathrm{sd}_{\mathrm{i}}=\mathrm{l}_{\mathrm{i}} / 1\right)$, and it increased when the standard deviation decreased $\left(\right.$ e.g. $\left.\mathrm{sd}_{\mathrm{i}}=\mathrm{l}_{\mathrm{i}} / 5\right)$. We think this chaotic behaviour is due to the approximations applied in the cumulative distribution function of short-lived products with average lifespan close to the time steps of 1 year utilized in this study.

\subsection{Policy recommendations}

First, recommendations by the IPCC (IPCC 2014) suggest starting spin-up simulations at 1900. However, this interval may be too short, possibly leading to underestimation of the current amount of carbon stored in long-lived wood products. Next, although strategies of increasing average lifespan and recycling rate are compatible, we recommend policy-makers to focus their efforts on working to increase the recycling rate of short-lived products, because global objectives of reducing atmospheric carbon concentrations are calculated according to short- to medium-term needs. However, extending lifespan of all wood products will reduce GHG emissions in longer terms.

Increasing the allocation of harvested wood to long-lived products could be one effective strategy to increase the average lifespan of wood products in general. High recycling rates could be achieved in the future if new categories of engineered wood, such as cross laminated timber (which is not treated with chemical preservatives), may be recycled several times over long periods. In view of this, the design of new products should implement a cascade concept, focusing on reducing the costs of wood waste collection and processing. This would facilitate the re-use of recycled material and the manufacture of new products.

Acknowledgments The research leading to these results has been supported by the EU through the Marie Curie Initial Training Networks (ITN) action CASTLE, grant agreement no. 316020. The contents of this publication reflect only the authors' views, and the European Union is not liable for any use that may be made of the information contained therein.

We also acknowledge the useful comments provided by the anonymous reviewers which contributed to the quality of this study.

\section{References}

Barredo JI, San Miguel J, Caudullo G et al (2012) A European map of living forest biomass and carbon stock. Ispra, Italy, p. 16.

Brunet-Navarro P, Jochheim H, Muys B (2016) Modelling carbon stocks and fluxes in the wood product sector: a comparative review. Glob Chang Biol 22(7):2555-2569

Dewar RC, Cannell MGR (1992) Carbon sequestration in the trees, products and soils of forest plantations: an analysis using UK examples. Tree Physiol 11(1):49-71

Eggers T (2002) The impacts of manufacturing and utilisation of wood products on the European carbon budget. E.F.I, Joensuu, p. 90

Eriksson E, Gillespie AR, Gustavsson L, et al. (2007) Integrated carbon analysis of forest management practices and wood substitution. Can J For Res-Rev Can Rech For 37(3):671-681

Food Agriculture Organization of the United Nations (2014) FAOSTAT. Rome, Italy. http://faostat.fao. org/default.aspx

Fortin M, Ningre F, Robert N, et al. (2012) Quantifying the impact of forest management on the carbon balance of the forest-wood product chain: a case study applied to even-aged oak stands in France. For Ecol Manag 279(0):176-188 
Garcia M, Riano D, Chuvieco E, et al. (2010) Estimating biomass carbon stocks for a Mediterranean forest in Central Spain using LiDAR height and intensity data. Remote Sens Environ 114(4):816830

Harmon ME, Harmon JM, Ferrell WK, et al. (1996) Modeling carbon stores in Oregon and Washington forest products: 1900-1992. Clim Chang 33(4):521-550

Höglmeier K, Weber-Blaschke G, Richter K (2014) Utilization of recovered wood in cascades versus utilization of primary wood - a comparison with life cycle assessment using system expansion. Int $\mathrm{J}$ Life Cycle Assessment 19(10):1755-1766

Höglmeier K, Steubing B, Weber-Blaschke G et al (2015) LCA-based optimization of wood utilization under special consideration of a cascading use of wood. J Environ Manag 152(0):158-170.

IPCC (2013) Summary for policymakers. In: Stocker TF, Qin D, Plattner G-K, Tignor M, Allen SK, Boschung J, Nauels A, Xia Y, Bex V, Midgley PM (eds) Climate change 2013: the physical science basis contribution of working group I to the fifth assessment report of the intergovernmental panel on climate change. Cambridge University Press, Cambridge and New York, pp. 1-29

IPCC (2014) 2013 Revised Supplementary Methods and Good Practice Guidance Arising from the Kyoto Protocol, Intergovernmental Panel on Climate Change, Hayama, Japan.

Karjalainen T, Kellomaki S, Pussinen A (1994) Role of wood-based products in absorbing atmospheric carbon. Silva Fenn 28(2):67-80

Karjalainen T, Pussinen A, Liski J, et al. (2003) Scenario analysis of the impacts of forest management and climate change on the European forest sector carbon budget. For Policy Econ 5(2):141-155

Klein D, Höllerl S, Blaschke M, et al. (2013) The contribution of managed and unmanaged forests to climate change mitigation - a model approach at stand level for the main tree species in Bavaria. Forests 4(1):43-69

Knauf M, Köhl M, Mues V et al (2015) Modeling the CO(2)-effects of forest management and wood usage on a regional basis. Carbon Balance Manag 10(13).

Kohlmaier G, Kohlmaier L, Fries E, et al. (2007) Application of the stock change and the production approach to harvested wood products in the EU-15 countries: a comparative analysis. Eur J For Res 126(2):209-223

Kurz WA, Apps MJ, Webb TM et al (1992) The carbon budget of the Canadian forest sector: phase I. p. 93. For. Can. NR, North. For. Cent., Edmonton, Canada.

Mantau U (2012) Wood flows in Europe (EU27). p. 24. Celle.

Mantau U, Saal U (2010) Material use. p. 19-34. Hamburg, Germany.

Marland E, Marland G (2003) The treatment of long-lived, carbon-containing products in inventories of carbon dioxide emissions to the atmosphere. Environ Sci Pol 6(2):139-152

Marland ES, Stellar K, Marland GH (2010) A distributed approach to accounting for carbon in wood products. Mitig Adapt Strateg Glob Chang 15(1):71-91

Mason Earles J, Yeh S, Skog KE (2012) Timing of carbon emissions from global forest clearance. Nature Clim Change 2(9):682-685

Muller DB, Bader H-P, Baccini P (2004) Long-term coordination of timber production and consumption using a dynamic material and energy flow analysis. J Ind Ecol 8(3):65-87

Pilli R, Fiorese G, Grassi G (2015) EU mitigation potential of harvested wood products. Carbon Balance Manag $10(6)$

Pingoud K, Soimakallio S, Perala AL et al (2003) Greenhouse gas impacts of harvested wood products. Evaluation and development of methods. p. $120+$ xvi. Espoo, Finland.

Schelhaas MJ, van Esch PW, Groen TA et al (2004) CO2FIX V 3.1-a modelling framework for quantifying carbon sequestration in forest ecosystems. p. 122. Wageningen, Netherlands.

Skog KE (2008) Sequestration of carbon in harvested wood products for the United States. For Prod J 58(6):5672

Smith JE, Woodbury PB, Heath LS (2004) Forest carbon sequestration and products storage, and Appendix C-1. In: US Agriculture and Forestry Greenhouse Gas Inventory: 1900-2001 p 80-93, Washington, US.

Waterworth RM, Richards GP (2008) Implementing Australian forest management practices into a full carbon accounting model. For Ecol Manag 255(7):2434-2443

Werner F, Taverna R, Hofer P, et al. (2006) Greenhouse gas dynamics of an increased use of wood in buildings in Switzerland. Clim Chang 74(1-3):319-347

Werner F, Taverna R, Hofer P, et al. (2010) National and global greenhouse gas dynamics of different forest management and wood use scenarios: a model-based assessment. Environ Sci Pol 13(1):72-85

Wiesmeier M, Sporlein P, Geuss U, et al. (2012) Soil organic carbon stocks in Southeast Germany (Bavaria) as affected by land use, soil type and sampling depth. Glob Chang Biol 18(7):2233-2245

Winjum JK, Brown S, Schlamadinger B (1998) Forest harvests and wood products: sources and sinks of atmospheric carbon dioxide. For Sci 44(2):272-284 